\title{
Multivariate analyses for biomarkers hunting and validation through on-tissue bottom-up or in-source decay in MALDI-MSI: application to prostate cancer
}

\author{
David Bonnel • Rémi Longuespee • Julien Franck • \\ Morad Roudbaraki • Pierre Gosset • Robert Day • \\ Michel Salzet • Isabelle Fournier
}

Received: 16 March 2011 /Revised: 12 April 2011 /Accepted: 12 April 2011 / Published online: 26 April 2011

(C) Springer-Verlag 2011

\begin{abstract}
The large amount of data generated using matrixassisted laser desorption/ionization mass spectrometric imaging (MALDI-MSI) poses a challenge for data analysis. In fact, generally about $1.10^{8}-1.10^{9}$ values $(\mathrm{m} / \mathrm{z}, \mathrm{I})$ are stored after a single MALDI-MSI experiment. This imposes processing techniques using dedicated informatics tools to be used since manual data interpretation is excluded. This
\end{abstract}

Published in the special issue MALDI Imaging with Guest Editor Olivier Laprévote.

Electronic supplementary material The online version of this article (doi:10.1007/s00216-011-5020-5) contains supplementary material, which is available to authorized users.

D. Bonnel $\cdot$ R. Longuespee $\cdot$ J. Franck $\cdot$ M. Salzet $(\bowtie) \cdot$

I. Fournier

MALDI Imaging team, Laboratoire de Spectrométrie de Masse

Biologique Fondamentale et Appliquée (FABMS), EA 4550,

Université Nord de France,

Université Lille 1,

59650 Villeneuve d'Ascq, France

e-mail: Michel.salzet@univ-lille1.fr

D. Bonnel $\cdot$ R. Longuespee $\cdot$ R. Day

Institut de pharmacologie de Sherbrooke, Faculté de médecine et des Sciences de la santé, Université de Sherbrooke,

Sherbrooke, QC J1H 5N4, Canada

M. Roudbaraki

INSERM, U-1003, Equipe labellisée par la Ligue Nationale contre le cancer, Université Nord de France,

Université Lille 1,

59650 Villeneuve d'Ascq, France

P. Gosset

Faculté Libre de Médecine, Laboratoire d'Anatomie et de Cytologie Pathologique du groupement hospitalier de l'Institut Catholique de Lille,

59000 Lille, France work proposes and summarizes an approach that utilizes a multivariable analysis of MSI data. The multivariate analysis, such as principal component analysis-symbolic discriminant analysis, can remove and highlight specific $\mathrm{m} / \mathrm{z}$ from the spectra in a specific region of interest. This approach facilitates data processing and provides better reproducibility, and thus, broadband acquisition for MALDI-MSI should be considered an effective tool to highlight biomarkers of interest. Additionally, we demonstrate the importance of the hierarchical classification of biomarkers by analyzing studies of clusters obtained either from digested or undigested tissues and using bottom-up and in-source decay strategies for in-tissue protein identification. This provides the possibility for the rapid identification of specific markers from different histological samples and their direct localization in tissues. We present an example from a prostate cancer study using formalinfixed paraffin-embedded tissue.

Keywords MALDI mass spectrometry imaging · Principal component analysis - Symbolic discriminant analysis . Hierarchical clustering · Bottom-up · In-source decay ·

Biomarkers $\cdot$ Prostate cancer

\section{Introduction}

Thirteen years after its original publication [1], matrixassisted laser desorption/ionization mass spectrometric imaging (MALDI-MSI) has become a commonly utilized tool for imaging endogenous biomolecules [2-5] and exogenous compounds [6-9] from a diverse array of tissue types. Since then, many improvements in MALDI-MSI performance have been achieved, including improvements 
related to tissue preparation [10-12], data processing and imaging software [13, 14], and spatial resolution [15, 16]. Biomarker discovery and identification has been a field of intense research over the past 10 years, and MALDIMSI has been proven to provide an interesting and promising strategy for such investigations [17-26]. However, large amounts of data are generated from imaging, and the manual determination of fine variations in marker regulation has become an impossible task with respect to the number of spectra generated (positionrastered) for a single image (frequently 20,000-40,000 pixels) and the number of images required to obtain a statistical overview that accounts for the sample variability between different experiments for a specific tissue and the intrinsic variability between tissues from different organisms. Moreover, each MS spectrum is composed of a large number of points (couple $(\mathrm{m} / \mathrm{z}, \mathrm{I})$ ), i.e., in general, a hundred thousand $\mathrm{m} / \mathrm{z}$ values with their corresponding intensity. All together, this corresponds to about $10^{8}-$ $10^{9} \mathrm{~m} / \mathrm{z}$ values and corresponding intensities for a unique image. Therefore, an understanding of the fine regulation of biomolecules to highlight markers of a specific physiological stage or cell phenotype requires the use of bioinformatics tools for fast and reliable analyses.

Multivariate statistics is a form of statistics that simultaneously encompasses the observation and analysis of more than one statistical variable. Methods of bivariate statistics, for example, ANOVA and $t$ tests, are special cases of multivariate statistics that involve two variables. There are several other types of multivariate analyses that are divided into two groups: descriptive methods and explorative methods. Descriptive methods include principal component analysis (PCA), factor analysis of correspondence, multiple correspondence analysis and classification methods such as hierarchical clustering. Explorative methods include multiple regression, discriminatory analysis and segmentation.

Considering the large amounts of data that are analyzed using the MALDI-MSI approach, data reduction and multivariable analysis has become a necessity in facilitating extraction of the information of interest. Among the different multivariable analytical tools that can be used for this purpose, PCA has been proven to provide an interesting method for automatic feature extraction [27]. Several studies have posited arguments that multivariable analysis though PCA is a good approach for this purpose and can be used with MALDI-MSI for pathological disease applications [18, 19, 28-30]. However, some limitations are associated with the use of PCA. These limitations encompass different factors, such as data analysis complications. In fact, many spectra can be similar for one principal component, whereas they can differ for another principal component, and thus, it is difficult to define the best data representation. This problem can be resolved by linking hierarchical clustering directly to PCA [18, 19, 28, 29].

In this paper, we developed a strategy, designated principal component analysis-symbolic discriminant analysis (PCA-SDA), to facilitate the identification of biomarkers. This concept of data mining was also applied to data sets generated for identification. In fact, protein identification using direct imaging strategies has been shown to be possible either by enzymatic digestion using tissue bottom-up approaches [10, 31, 32] or by in-source decay (ISD) with top-down approaches [33]. Such strategies also produce large quantity of data, and markers of interest may be masked within the forest of non-relevant data. Here, we explored the use of PCA-SDA analysis with data generated using both bottom-up and ISD. Finally, the strategy was applied to a biologically relevant case, namely prostate cancer, using samples from hospital libraries, i.e., formalin-fixed paraffin-embedded (FFPE) tissues.

\section{Experimental procedure}

\section{Materials}

Alpha-cyano-4-hydroxycinnamic acid (CHCA), sinapinic acid, trifluoracetic acid (TFA), ethanol (EtOH), acetonitrile (ACN), chloroform, aniline (ANI), ( $N$-succinimidyloxycarbonylmethyl)tris(2,4,6-trimethoxyphenyl)phosphonium bromide (TMPP), water CHROMASOLV PLUS for HPLC $\left(\mathrm{H}_{2} \mathrm{O}\right)$ were purchased from Sigma-Aldrich (Saint Quentin Fallavier, France). Sequencing-grade-modified trypsin, porcine enzyme was from Promega (Charbonnières-les-Bains, France)

Tissue preparation and treatment

\section{Frozen tissues}

Adult male Wistar rats weighing 250-350 g (animal use accreditation provided by the French ministry of agriculture No. 04860) and maintained under standard care were used. Animals were sacrificed by suffocation under $\mathrm{CO}_{2}$ and immediately dissected to remove the brain. Tissue sections $(10 \mu \mathrm{m})$ were obtained from frozen rat brains tissues using a Leica CM1510S cryostat (Leica Microsystems, Nanterre, France) and applied to ITO-coated conductive glass slides (Bruker Daltonics, Bremen, Germany). Tissues were then submitted to washing procedures prior to matrix application for improved detection of peptides/proteins. Washing was performed by two washing steps using first washing with cold $95 \%$ EtOH for $15 \mathrm{~s}$ followed by a washing step with chloroform for $1 \mathrm{~min}$ according to previously published protocols [11,34]. 


\section{FFPE tissues}

Prostate tissue specimens Prostate tissue specimens were obtained from patients undergoing radical prostatectomy for clinically localized prostate carcinoma. All patients gave informed consent according to a protocol approved by the Internal Review Board for research involving human subjects at Saint Philibert Hospital. All experiments involving patient tissues were carried out under approval number CP 01/33, issued by the Consultative Committee on Persons Protection in the Biomedical Research of Lille. None of the patients had any treatment for prostate cancer before surgery. Prostate tissues were fixed by placing the samples $(2.5 \mathrm{~cm} \times 2 \mathrm{~cm})$ for $24-48 \mathrm{~h}$ in neutral $3.7 \%(w / v)$ formalin solution, rinsed in PBS buffer and then were paraffin-embedded which allows tissues to be cut into thin (i.e., a few micrometers) sections. For MALDI imaging experiments, $10-\mu \mathrm{m}$-thick tissue sections were cut from the FFPE whole-mount prostate tissue block, placed on the ITO-coated slides, and heated for $60 \mathrm{~min}$ at $58{ }^{\circ} \mathrm{C}$. The paraffin was then removed by submerging the glass slide in toluene two times for $5 \mathrm{~min}$, followed by a light rehydration in ethanol $\left(100,96 ; 70\right.$, and $\left.30^{\circ} \mathrm{C}\right)$ baths before drying in a dessicator at room temperature. Tissue was also counterstained with Mayer's hematoxylin, dehydrated through graded ethanol solutions, and air-dried for the histological examinations by the anatomopathologists. According to the anatomopathology examinations, the tissues appeared heterogenous and contained cancer, hyperplasiae, and normal regions in addition to stromal tissues in each region.

Antigen retrieval Antigen retrieval (AR) process was performed to unmask proteins and ease access of the enzyme to its specific cleavage sites. Here, AR was performed using citric acid or so-called citric acid antigen retrieval (CAAR). CAAR was performed by immersing the slides in $10 \mathrm{mM}$ of citric acid for $20 \mathrm{~min}$ at $90{ }^{\circ} \mathrm{C}$ and then drying them in a dessicator for $10 \mathrm{~min}$. Prior to the enzymatic digestion, the slides were incubated in $10 \mathrm{mM}$ $\mathrm{NH}_{4} \mathrm{HCO}_{3}$ two times to remove the remaining AR solution and to condition the tissue for good enzyme activity.

\section{Enzymatic digestion}

Automatic trypsin digestions were performed using a high position accuracy chemical inkjet printer (CHIP-1000, Shimadzu Biotech, Kyoto, Japan) [10]. The printed array of the CHIP-1000 on the tissue section comprised spots spaced $250 \mu \mathrm{m}$ center-to-center. A total of $20 \mathrm{~nL}$ of a solution containing $25 \mu \mathrm{g} / \mathrm{mL}$ of trypsin in pure $\mathrm{H}_{2} \mathrm{O}$ was applied to each spot. Five droplets of approximately $100 \mathrm{pL}$ were deposited on each spot per cycle. Thus, 40 iterations were necessary to obtain the final volume. The tissue sections were then incubated at $37{ }^{\circ} \mathrm{C}$ for $2 \mathrm{~h}$ in a box with an atmosphere of saturated $\mathrm{MeOH} / \mathrm{H}_{2} \mathrm{O}(1: 1, v / v)$ to avoid drying the enzyme droplets.

\section{$N$-terminal derivatization}

Automatic TMPP derivatization was performed using the automatic microspotting device [10]. A CHIP-1000 was used to deposit TMPP on the tryptic spots according to the procedure that has been previously described for trypsin digestion. A total of $10 \mathrm{~nL}$ of solution containing $1 \mathrm{mg} / \mathrm{mL}$ of TMPP in $\mathrm{ACN} / \mathrm{H}_{2} \mathrm{O}(3: 7, v / v)$ was deposited on each spot. Five droplets of approximately $100 \mathrm{pL}$ were deposited on each spot per cycle. Thus, 20 iterations were necessary to obtain the final volume for each spot. A solution of $\mathrm{ACN} / \mathrm{H}_{2} \mathrm{O}$ containing $1 \%$ TEA was then spotted, thus initiating the derivatization reaction. The automated microspotting was performed either according to a global square area of points or by dividing this area into smaller squares, with each including ten-by-ten spots to increase the reaction yield [10].

\section{MALDI-MSI}

Depending on whether the bottom-up or the ISD approaches were used, solutions specific for the matrices were deposited using the CHIP-1000 printer [10] or the ImagePrep sprayer.

\section{Bottom-up approach}

A solid ionic matrix $\mathrm{CHCA}$ /aniline was used as the matrix to image peptides and was prepared according to a previously established procedure [35].

Matrix microspotting Forty nanoliters of ionic matrix solution containing $10 \mathrm{mg} / \mathrm{mL}$ of $\mathrm{CHCA}$, and $7.2 \mu \mathrm{L}$ of aniline in $0.1 \%$ ACN/TFA $(6: 4, v / v)$ was spotted on each spot. Five droplets of approximately $100 \mathrm{pL}$ were deposited on each spot per cycle. Thus, 20 iterations were necessary to reach the total final volume.

Matrix micro-spraying Five milliliters of a solution containing $10 \mathrm{mg} / \mathrm{mL}$ of the matrix $\mathrm{CHCA} /$ aniline in $0.1 \%$ ACN/TFA $(3: 2, v / v)$ was prepared. The matrix was deposited on the tissue section with the ImagePrep automatic sprayer (Bruker Daltonics, Bremen, Germany), which creates an aerosol via vibrational vaporization and allows one to monitor the different stages of matrix deposition, i.e., extraction, drying and matrix layer thickness. Indeed, the method used to spray CHCA/ aniline included an initialization phase to deposit the first 
layer of the matrix on the slide. This process was followed by phases that permitted partial moisturization over several cycles of the tissue section before it had dried completely. The methods and parameters set-up are given in Table 1.

MS/MS identification in using bottom-up strategies MS/MS experiments on digested tissue were performed using the UltraFlex II MALDI-TOF/TOF instrument equipped with LIFT III cell using FlexAnalysis 3.0. For MS/MS experiments, parameters were set as follow: laser repetition rate was $100 \mathrm{~Hz}$, ion source voltages were, respectively, 8 and $7.3 \mathrm{kV}$ on MALDI sample plate and first electrode; LIFT cell was pulsed from ground for electrodes 1 and 2 to $19 \mathrm{kV}$ and in the last step, electrode 3 was decreased to $3.2 \mathrm{kV}$; reflector end voltage was set to $29.5 \mathrm{kV}$ and midgrid to $13.85 \mathrm{kV}$. For each MS/MS spectrum, 10,000 total shots were averaged including 1,000 for parent ions and 9,000 for fragments. Laser fluence was increased over the experiments for generating lower $\mathrm{m} / \mathrm{z}$ fragments.

Data analysis Protein identification in databanks were performed using Biotools 3.0 (Build 1.88) software (Bruker Daltonics, Bremen, Germany) connected to Mascot 2.2.0.3 search engine and interrogating the Swiss-Prot Protein Knowledgebase Release 56.1 of 02-Sep-2008 (397,539 sequence entries, comprising 143,289,088 amino acids abstracted from 172,934 references) with oxidation as variable modification and no fixed modification. Taxonomy was specified to be human. Trypsin was selected as enzyme and one missed cleavages were selected. The mass tolerance was set at 0.4 and $0.4 \mathrm{Da}$, respectively, for the MS and MS/MS.

\section{In-source decay approach}

The 1,5-diaminonaphthalene (1,5-DAN)/camphor was used as the ionic matrix to image ISD fragments of proteins. It was prepared by adding 1 eqM of cyclic terpenoid camphor to $5 \mathrm{mg} / \mathrm{mL} 1,5$-DAN in $2 \%$ ACN/TFA0 $(1: 1, v / v)$.
Matrix microspotting Twenty nanoliters of a solution containing $5 \mathrm{mg} / \mathrm{mL}$ of the matrix 1,5-DAN/camphor in $0.2 \% \operatorname{ACN} / \operatorname{TFA}(1: 1, v / v)$ was deposited on an array of spots that were $100 \mu \mathrm{m}$ in size and spaced $200 \mu \mathrm{M}$ in a hemi rat brain section, using a chemical inkjet printer CHIP 1000 (Shimadzu, Kyoto, Japan).

Matrix micro-spraying Matrix micro-spraying for ISD was performed following the same protocol as described for MALDI-MSI and using $5 \mathrm{~mL}$ of a solution containing $5 \mathrm{mg} / \mathrm{mL}$ of the solid ionic matrix 1,5-DAN/camphor in ACN/TFA $0.2 \%(1: 1 v / v)$.

Image acquisition Images were acquired using the UltraFlex II MALDI-TOF/TOF instrument. Imaging was performed in the positive reflectron mode, and MALDI-MS spectra were acquired in the $\mathrm{m} / \mathrm{z}$ range from 550 to 5,000. A total of 300 spectra were acquired for each spot at a laser frequency of $100 \mathrm{~Hz}$. The images were recorded and reconstructed using Fleximaging 2.1 software.

Statistical analysis The data set obtained with Fleximaging v2.1 software (Bruker Daltonics, Bremen) was loaded in the soft ClinProTools v2.2 (Bruker Daltonics, Bremen) to conduct a principal component analysis and hierarchical clustering of the data. The unsupervised method was selected for the PCA after standardization of the data. Thus, PC1 and PC2 were found to have the largest variance. After the hierarchical clustering, the same data were exported to the image in Fleximaging 2.1 to view areas with different profiles.

\section{Results and discussion}

Determining specific markers of a physiological stage or cell phenotype using MALDI-MSI requires the use of data processing and data analysis using multivariable analytical bioinformatics tools. The most widely used multivariable analysis is PCA. PCA provides access to $\mathrm{m} / \mathrm{z}$, which

Table 1 Vibrational micro-sprayer method used for matrix deposition giving method parameters used for the experiments including sensor control final voltage, number of cycles, spray time, incubation time and dry mode

\begin{tabular}{llllll}
\hline & Sensor control: final voltage difference & Number of cycles & Spray time & Incubation time & Dry mode \\
\hline Phase1: Initialization & $0.65 \mathrm{~V}$ & 5 to 20 & $2.5 \mathrm{~s}$ & $10 \mathrm{~s}$ & $90 \mathrm{~s}$ \\
Phase2 & $0.1 \mathrm{~V}$ & 2 to 10 & $2 \mathrm{~s}$ & $30 \mathrm{~s} \pm 30 \mathrm{~s}$ & $60 \mathrm{~s}$ \\
Phase3 & $0.2 \mathrm{~V}$ & 4 to 12 & $1 \mathrm{~s}$ & $30 \mathrm{~s} \pm 30 \mathrm{~s}$ & Residual wetness \\
Phase4 & $0.3 \mathrm{~V}$ & 3 to 30 & $1 \mathrm{~s}$ & $30 \mathrm{~s} \pm 30 \mathrm{~s}$ & Residual wetness \\
Phase5 & $0.6 \mathrm{~V}$ & 4 to 64 & $1 \mathrm{~s}$ & $30 \mathrm{~s} \pm 30 \mathrm{~s}$ & Residual wetness \\
\hline
\end{tabular}


demonstrates differences between or within samples. PCA is often combined with hierarchical clustering ( $\mathrm{HC}$ ), because $\mathrm{HC}$ classifies the mass spectra according to similarities between their profiles and thus provides the ability to highlight regions containing differences in molecular content. Figure 1 describes the general application of the analytical workflow to MALDI-MSI data sets.

The first approach of MALDI-MSI data sets is based on the supervised or non-supervised PCA mode, which allows the detection of $\mathrm{m} / \mathrm{z}$ that demonstrate important variations within the tissue. PCA is conducted using Pareto scaling, which uses the square root of the standard deviation as a scaling factor to reduce the dominance of large-scale intensity changes in the matrix and other high-abundance ions, which may mask the variation in lower abundance ions during PCA. The overall outcome of the PCA is greatly affected by the ability of ions related to the matrix coating and other endogenous molecules to mask the underlying, relevant information. For the unsupervised PCA, each spectrum is classified individually. Thus, the selected PCs account for the greatest separation of each individual spectrum. At the top of each, the scores and loading plots are shown. In the second approach, we propose the use of hierarchical clustering (Fig. 1) as an initial step to identify major spectral difference between each histological type. This method determines the discriminatory signals and builds functions using these signals that distinguish sample populations based on their classification. Peak lists from MALDI spectra, which were obtained using data processing software (Flex Analysis v3.0 and Flex Control v2.5), were used for the statistical analyses and were clustered by similarity discrimination based on presence vs. absence as criteria. Statistical analyses were conducted using PCA with ClinProTools

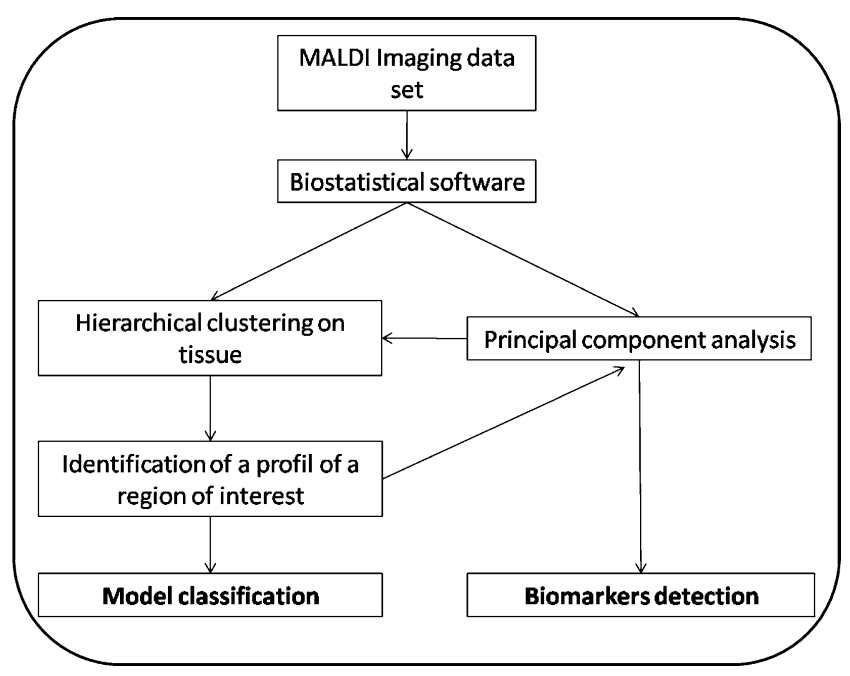

Fig. 1 General workflow to search for biomarkers and model classification by MALDI-MSI v2.2 software. In this case, the mass spectra were internally recalibrated on common peaks (also known as a spectral alignment) and normalized to the total ion count. An average spectrum created from all of the individual spectra was used to perform peak selection and to define the integration ranges. The integration ranges were used to determine intensities or areas of single spectra. The signal intensities were used for all calculations. For PCA and HC, the individual peak intensities were standardized across the database.

PCA-SDA based on hierarchical clustering for biomarker identification

PCA-SDA based on $\mathrm{HC}$ was first tested using the data sets from an image generated from a rat brain tissue section under analytical conditions to detect peptides and small proteins. Following MALDI imaging acquisition, the data were loaded in the analytical software for HC (Fig. 2). HC was prepared using a Euclidean distance method and a ward linkage method based on the PCA results previously obtained. The dimensions were reduced to $85 \%$ of the explained variance. A dendrogram was then obtained (Fig. 2A), which could be translated into a molecular image by allocating a specific color plot to each of the different clusters of the HC dendrogram, as presented in Fig. 2B. The molecular image generated from the $\mathrm{HC}$ results could be

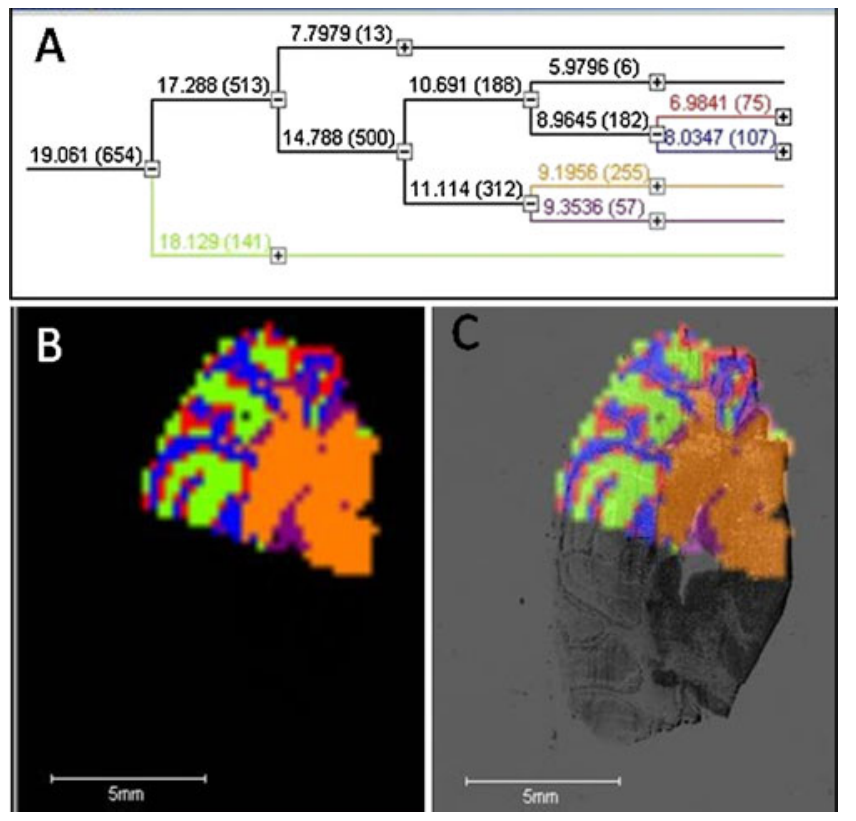

Fig. 2 Hierarchical clustering applied to a frozen rat brain MALDI image. Colors correspond to the different clusters found in the dendrogram. A Dendrogram obtained from the image data set. B Image representation of clusters of the spectra generated by hierarchical clustering based on the PCA results. C Superposition of the clustering on the rat brain tissue section optical image 
superimposed on the optical image of the tissue section (Fig. 2C) and showed a clear correlation of the different clusters to the histological tissue types. Each group of spectra delimitating a cluster differed from other groups based on spectral profiles convergence for classified in the same cluster and divergence for spectra classified in different clusters (Fig. 2B). This is a good method to define regions corresponding to various cell phenotypes and subsequently markers of these specific phenotypes. We, therefore, used HC to define our regions of interest (ROI's). To exemplify this, we created a ROI (Fig. 3) in the rat brain section for the fourth ventricle. Here, we choose to enclose in the ROI a slightly larger area than the fourth ventricle to include spectra with different profiles for serving as negative controls (Fig. 3A). Spectra for this region were then selectively loaded for PCA multivariate analysis (Fig. 3B). After PCA analysis, the PC1 versus PC2 loading was performed to compare $\mathrm{m} / \mathrm{z}$ that were differentially detected in the selected ROI because $\mathrm{PC} 1 / \mathrm{PC} 2$ provided the best discrimination. Several different ions presented a high level of discrimination along the PC1 axis. To perform a study case, two ions with a high level of discrimination and that presented a very different distribution within the tissue sections were selected: ions at $\mathrm{m} / \mathrm{z} 2,030$ and $\mathrm{m} / \mathrm{z} 2,793$. As demonstrated by the superimposition of the MALDI images of these ions onto the optical image of the tissue section (Fig. 3C and D), these ions had a very different distribution. In fact, $m / z$ 2,030 was specific to the fourth ventricle (Fig. 3C), whereas $\mathrm{m} / \mathrm{z}$ 2,793 (Fig. 3D) demonstrated a relatively large distribution within the tissue section that corresponded to other morphological structures in the tissue. $m / z 2793$ was absent in the fourth ventricle but present in the area obtained from the ROI around the structure, which served as a negative control. The MALDI-

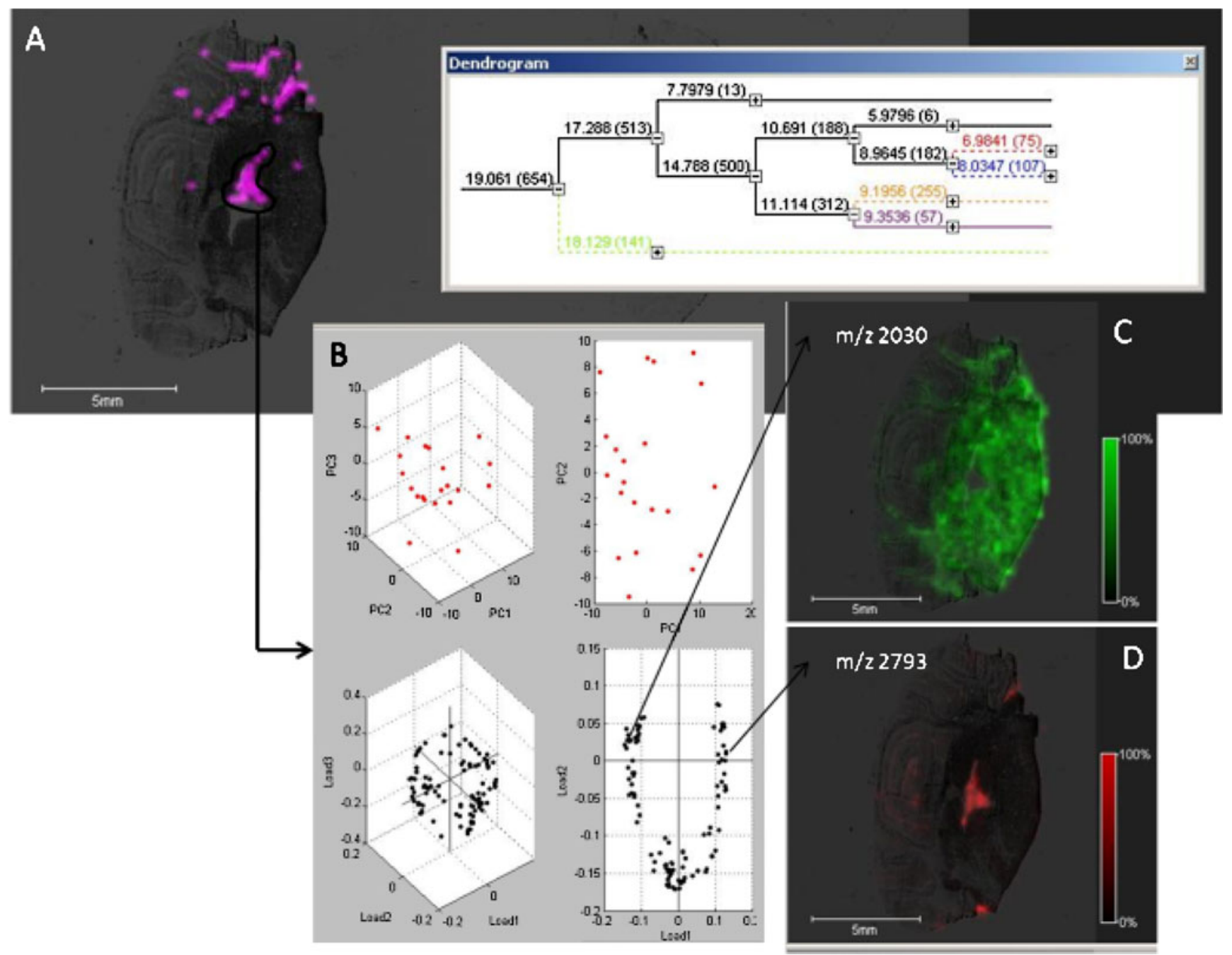

Fig. 3 Selection of a cluster representing the ROI. A The spectra for this region were loaded for a new PCA analysis to provide the different $\mathrm{m} / \mathrm{z}$ variations. B Examples of images at $\mathrm{m} / \mathrm{z}$ with different distributions, as demonstrated by the PCA analysis. C-D Images of the distributions at $\mathrm{m} / \mathrm{z} 2030$ and $\mathrm{m} / \mathrm{z} 2793$, respectively 
MSI results are usually obtained from the average mass spectrum, which is reconstructed from all of the spectra recorded during the image acquisition using the software. Therefore, by using such a representation of the data, the $\mathrm{m} / \mathrm{z}$ present in a small region (i.e., in a few spectra) are not properly represented in the average mass spectrum, even if they are very intense. This lack of information is exemplified by the signal at $m / z 2,793$, is not observed in the average mass spectrum (Fig. 4A) and precludes the reconstruction of an image. However, as shown in Fig. 4B, it was possible to detect this ion specifically in the fourth ventricle using the PCA-SDA analytical approach described herein (Fig. 4C), which is in contrast to other regions (Fig. 4D).

Thus, without the PCA-SDA approach, it would not have been possible to detect the presence of this marker, which is highly specific to the 4 th ventricle. This shows that PCA-SDA facilitates the direct tracking of specific markers in an ROI defined by the $\mathrm{HC}$ analysis. As compared to other proteomic techniques, this will greatly affect the MSI. In fact, the great potential of MSI coupled with PCA-SDA is reflected by the ability to quickly detect specific markers that are present in a pathological region or in regions containing cells with diverse phenotypes while conserving their spatio-temporal localization in the tissue. These signals would be diluted using classical proteomic strategies in which whole organs are used for extraction. For all experiments performed on rat brains, biological material was easily accessible and these experiments were performed in triplicate from adjacent tissue section from the same tissue block and from five different brain tissues from different animals. Similar results were obtained from the multivariate analysis approach from the different experiments. However, only some examples on various tissues are presented here. The next step is the identification of the detected markers in tissues. Therefore, we were interested in testing the PCA-SDA strategy using data generated from identification strategies.
Bottom-up approach

The bottom-up strategy was the first technique explored for on-tissue protein identification $[10,32,35,36]$. This is explained principally based on two factors: it is difficult to use a proper top-down analysis with ion selection on MALDI instruments, and archived clinical samples (FFPE) cannot be used for MSI without a digestion step [35, 37, 38]. Therefore, marker screening from a classical MSI sequence is performed. However, bottom-up and classical approaches have been shown to lead to complementary data with proteins specifically observed in one strategy. Moreover, marker screening for archived FFPE samples can only be performed using digestion data. Therefore, the validity of statistical analyses from such data, which could be hampered by a slight delocalization of markers due to the type of tissue preparation, must be investigated.

PCA and HC from enzymatic digestion data To evaluate the digestion data, a rat brain tissue section (interaural, $7.20 \mathrm{~mm}$, bregma, $1.80 \mathrm{~mm}$ ) was subjected to trypsin digestion prior to matrix deposition (Fig. 5A and C). After PCA analysis, hierarchical clustering was applied to the data set. The results of the clustering are presented in Fig. 5B, and the dendrogram is shown in Fig. 5D. The image reconstructed from the clustering demonstrated a good correlation with the different brain areas determined in the brain section (Fig. 5A, C). The presented images had a low resolution due to one of the drawbacks of the software used (the number of data points accepted by the software). Therefore, HC imaging analysis data sets with a poor resolution (962 points at $250 \mu \mathrm{m}$ ) were recorded. This confirmed that a bottom-up strategy could be used for protein identification in tissues and was statistically relevant.

$H C$ and $N$-terminal derivatization To simplify the protein identification procedure, derivatization strategies were

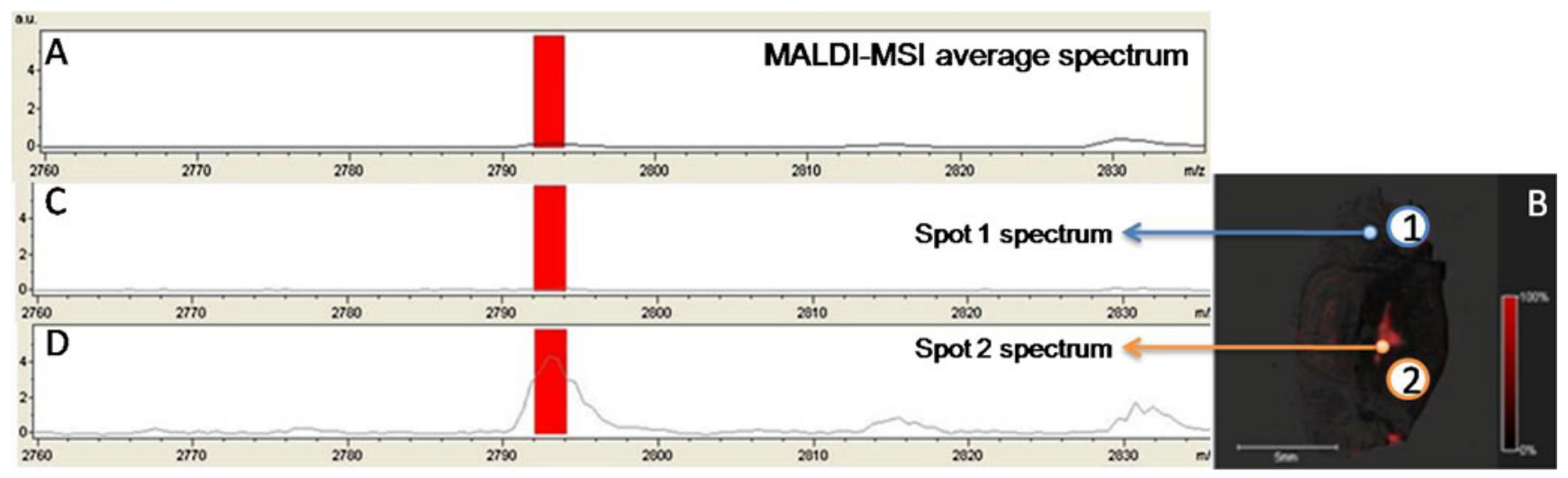

Fig. 4 A MALDI images of the average spectrum with a zoom in the $m / z$ range of the ions at $m / z$ 2,793, which are non-detectable. B Image of the $m / z$ 2,793 ion distribution. C-D Single MALDI spectra recorded in the region where $m / z 2793$ is found (C) and not found (D) 
Fig. 5 A Optical image and $\mathbf{C}$ image from the brain atlas of the rat brain tissue section used in the bottom-up experiment with on-tissue trypsin digestion. D $\mathrm{HC}$ dendrogram showing the differentiation of the different histological images and B HC image reconstructed from $\mathrm{HC}$ dendrogram data

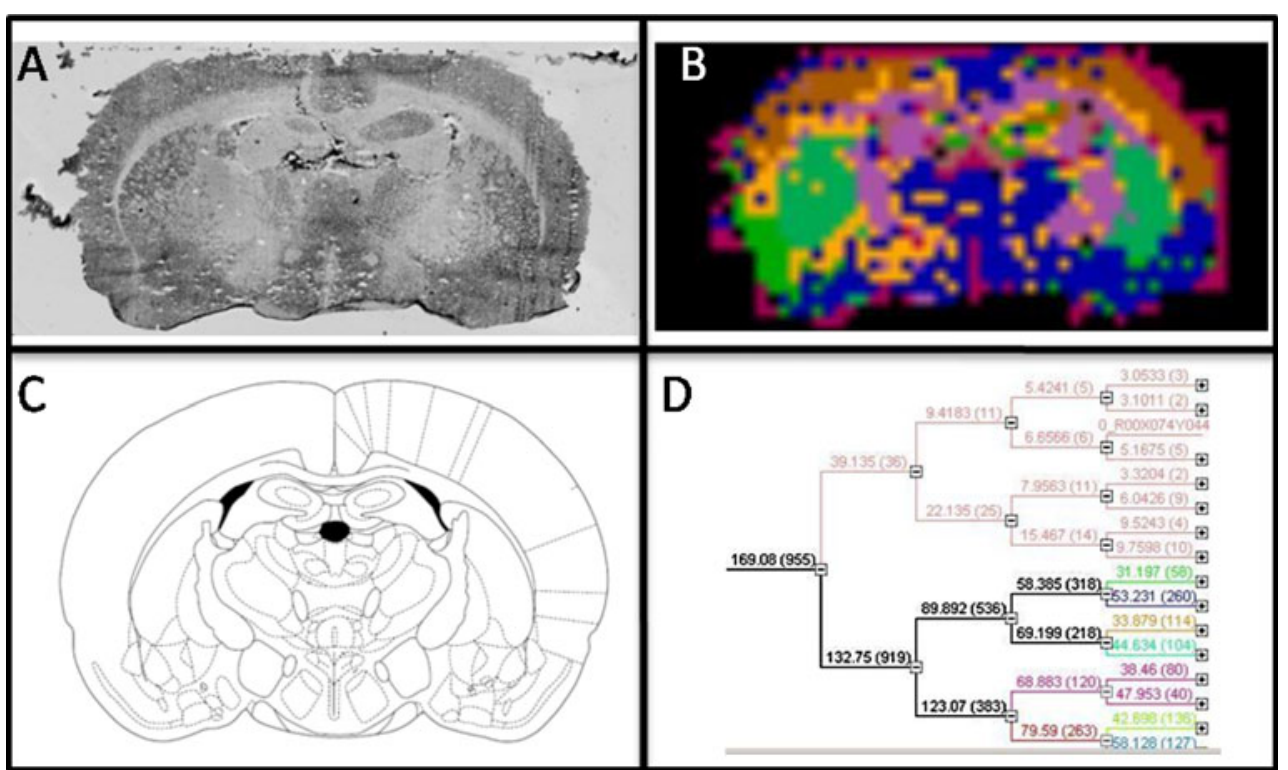

developed in the group to be performed on digestion peptides [32]. N-terminal chemical derivatization of peptides was developed in order to help in proteins identification by unambiguous determination of digestion peptides primary sequence. In fact addition of specific chemicals at the N-terminus of peptides, in peculiar positively or negatively charged groups, have shown to increase fragmentation ion yields and lead to orientation of fragmentation towards specific ion fragment series. This results in MS/MS spectra of much easier interpretation even for de novo sequencing, giving more confident identifications. Previously, several derivatization procedures were developed to be performed in situ at the tissue level [32] showing the interest of both derivatization by negative charge (derivatization with 4SPITC (4-sulfophenyl isothiocyanate) or 3-SBASE (3sulfobenzoic acid succinimidyl ester)) or positive charge (addition of TMPP ( $N$-succinimidyloxycarbonylmethyl)tris(2,4,6 trimethoxyphenyl)phosphonium bromide). Although if all derivatizations were usable at the global tissue level, only TMPP was found to be easily compatible with automatic micro deposition methods preventing delocalization of peptides during the derivatization process and subsequently allowing images to be recorded. Therefore, TMPP derivatization was chosen here to be used for multivariate analysis studies. In the present study, we tested PCA and $\mathrm{HC}$ on MALDI imaging data recorded from a rat brain tissue section (interaural, $4.84 \mathrm{~mm}$, bregma, $4.16 \mathrm{~mm}$ ) following micro-spotting trypsin digestion and then micro-spotting TMPP derivatization, as compared to micro-spotting of trypsin alone (Fig. 6). In this experiment, two distinct areas that were symmetrical according to the symmetry axis of the rat brain were digested (Fig. 6B) and then derivatized (Fig. 6C). As demonstrated, the classification resulting from $\mathrm{HC}$ discriminated two regions, each of which was represented by a branch of the dendrogram. The first branch (red) corresponds to the cortex, whereas the second branch (blue) corresponds to the spectra depicting the corpus callosum. From the two dendrograms, it is clear that enzymatic digestion alone and enzymatic digestion followed by N-terminal chemical derivatization provide the same data classification. This result demonstrates that all types of data can be used for statistical analysis if the data is of sufficient quality, i.e., if the particular treatment used does not induce delocalization of the molecules.

\section{In-source decay approach}

The bottom-up approach is the most advanced and most widely used technique for protein identification and characterization because most instruments permit fragmentation of the amino acid sequence in the mass range of 500 3,500. Nevertheless, there are several fundamental and practical limitations to the bottom-up strategy. Most importantly, only a fraction of the total peptide population for a given protein is identified, and therefore, only a portion of the information for the protein sequence is provided. It is clear from genomic studies that each openreading frame can give rise to many protein isoforms that originate from alternatively spliced products, and each isoform can present different types and locations of posttranslational modifications (PTMs). PTMs such as phosphorylation and glycosylation are known to be important in the regulation of protein function and cell 
Fig. 6 A Optical image of a rat brain tissue section presenting two pitches that are symmetrically distributed and that correspond to a specific tissue preparation: enzymatic digestion (left) and enzymatic digestion followed by TMPP derivatization (right). HC was applied to the MALDI-MSI data for the two conditions, and the corresponding dendrogram and reconstructed images are presented $\mathbf{B}$ for trypsin digestion and $\mathbf{C}$ for trypsin digestion followed by TMPP derivatization

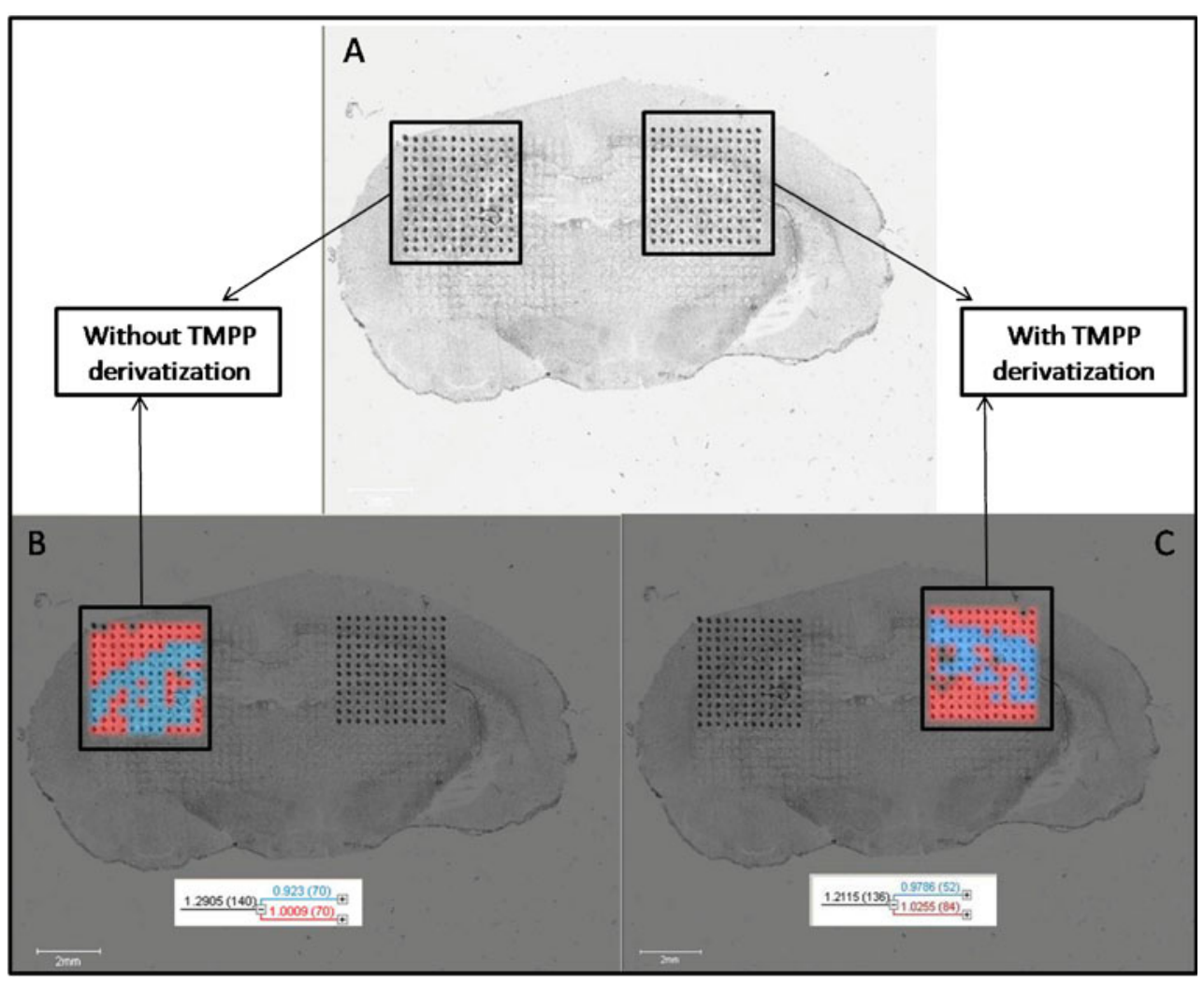

metabolism. A consequence of the limited sequence coverage in bottom-up proteomics is the global loss of information, including information concerning PTMs. In contrast, the top-down strategy provides potential access to a large part, and sometimes all, of the protein sequence, including its PTMs [39-45]. In addition, the timeconsuming protein digestion step required for the bottomup method is eliminated.

Classical top-down strategies are not possible using MALDI instruments because the instrumentation used for such purposes is not compatible with the very low charge states observed in MALDI. However, the top-down method without ion selection can be used with MALDI to rapidly generate fragmentation using ISD [39-46]. ISD has been demonstrated previously [33] for tissue sections. However, because ISD is not used with ion selection, the resulting mass spectra are extremely difficult to interpret. Here, we tested the ability of $\mathrm{HC}$ and PCA to facilitate interpretation of the ISD data. A previous publication has demonstrated the advantage of using a 1,5-DAN matrix for protein sequence and glycosylation characterization. The 1,5-DAN matrix is a good proton donor and tends to fragment proteins from their $\mathrm{C}$-terminal region to produce $\mathrm{ci}^{+}$and $\mathrm{zi}^{+}$ fragment ions [47]. In the present study, we developed a specific solid ionic matrix (1,5-DAN/camphor) to achieve better reproducibility, sensitivity and deposition facility by micro-spraying or micro-spotting of the matrix for ISD from tissues. We found that adding the camphor cyclic terpenoid to the classical 1,5-DAN matrix resulted in average spectra with more intense peaks, which were found to be ISD ions. This process facilitated the detection of ions that corresponded to the tags used for protein identification in the images (Electronic Supplementary Material Fig. S1). This ionic matrix was also used for instrumentation preservation, and it demonstrated greater solubility in solvents that are classically used with automated microspraying and micro-spotting devices; 1,5-DAN alone was shown to be a matrix with a high level of deterioration for the deposition instruments.

PCH and HC for ISD-MALDI-MSI Clustering images (Fig. 7) were generated from the obtained MALDI images using 1,5-DAN/camphor, and subsequently, prompt fragments were obtained from whole proteins in the section at each position. Two different deposition methods for the matrix, the micro-spotter and the micro-sprayer, were used. The hierarchical clustering results are shown in Fig. 7A and $\mathrm{C}$. The histological regions corresponding to the clusters are demonstrated symmetrically in Fig. 7B and D. We note that the classification of the spectra correlated with the histological areas of the tissue section. These clusters would not be detected if there were no differences between the spectra determined for each area. Therefore, it is possible to classify the specific ions by PCA and to reassemble them with greater ease to identify proteins of interest while suppressing common ions of the different 
Fig. $7 \mathrm{HC}$ analysis performed for MALDI-MSI data recorded in ISD from a rat brain tissue section using a 1,5-DAN/camphor ionic matrix deposited with an automatic micro-spotter (A) and with an automatic microsprayer (C). (B and D)

Schematic representation of the spectral classification for each cluster. Green: cingulum, red: dentate gyrus, blue: combination of cerebral cortex and hippocampus
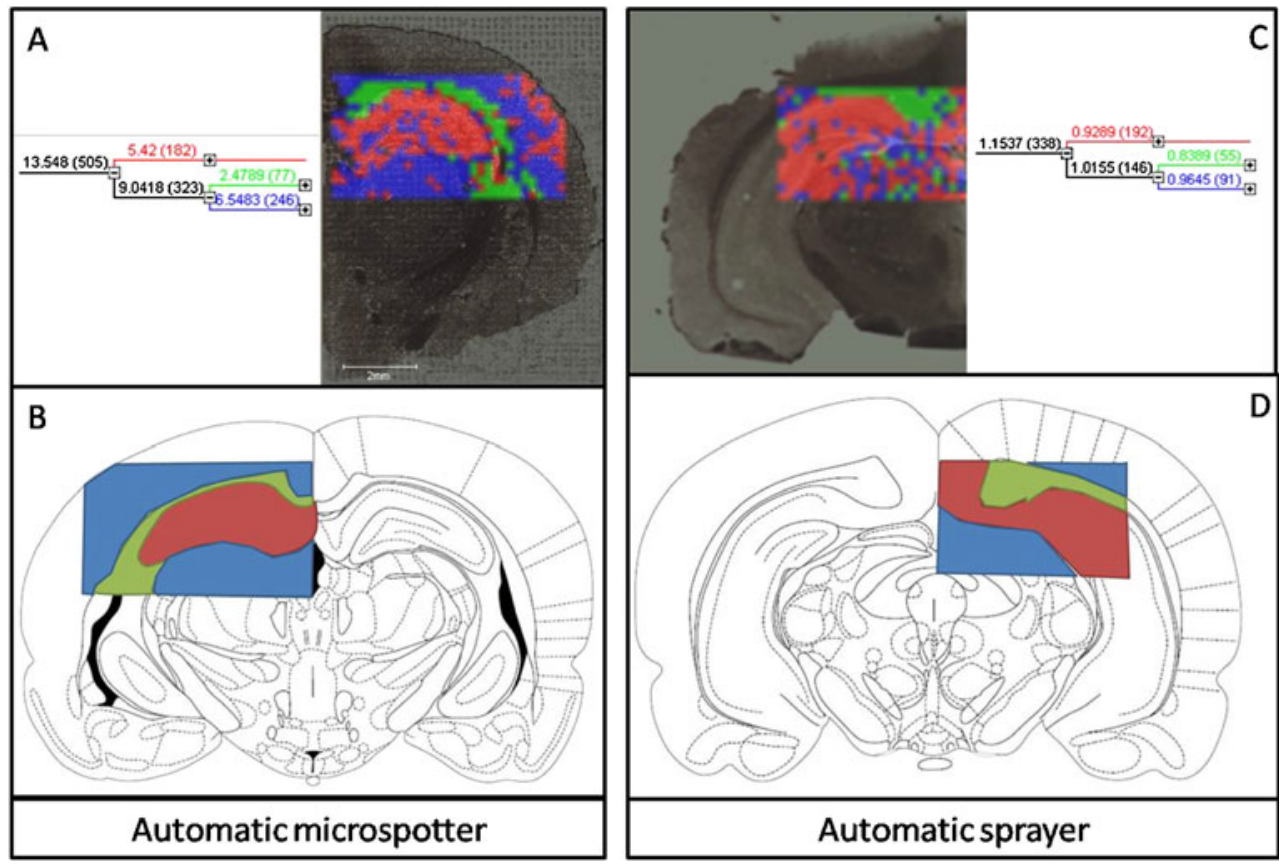

class (common proteins). Unfortunately, we identified only myelin in the cingulum region of the rat brain section (Electronic Supplementary Material Fig. S1) using this technology. Moreover, it was often difficult to analyze properly one of the amino acid sequences within a spectrum ISD due to the large number of peaks that were detected for the different proteins. Thus, using HC, we were able to identify differences between histological regions and PCA, which permitted the efficient detection of differences in the complexity of the ISD spectra. Importantly, ISD can be only performed using frozen tissue (never formalin-fixed paraffin-embedded tissues), and only major proteins with a high abundance can be detected. The developments of ontissue depletion methods are clearly necessary to further the uses of such techniques.

PCA and HC in the bottom-up approach: application to FFPE prostate cancer tissues

The opportunity to investigate archived FFPE tissues will pave the way toward a gold mine of tissue samples that are stored in pathological institutes for retrospective studies. Consequently, many efforts by others and by our group [35, 37] have been implemented to find a strategy to analyze tissues using MALDI-MSI [37, 48-50]. Most of the libraries are builds of FFPE tissues because this preservation protocol produces well-conserved morphology and high stability along time avoiding degradation of molecules. However, the major difficulty associated with such tissue is the occurrence of protein cross-linking due to tissue fixation. Indeed, formalin creates methylene bonds between proteins and prevents direct tissue analysis by MALDI-MSI. To circumvent this problem, enzymatic digestion using, for example, trypsin is used to obtain and to identify protein fragments, and therefore, a bottom-up approach is used [35]. Because cross-linking is still pursuing in FFPE tissue blocks during conservation period, protein accessibility becomes more difficult over time, and enzyme cleavage can be affected leading to poor enzymatic yields. Therefore, it is necessary to establish processes that facilitate access to proteins. Similar challenges are encountered for HIC of FFPE samples. Over time, many different protocols have been developed to unmask antigen epitopes [24, 51-60]. These so-called AR processes are still not well understood in terms of the associated molecular changes. The most reasonable hypothesis is that AR allows changes in the conformation of cross-linked proteins and thus facilitates access to sites within the proteins. To date, many different AR protocols have been published [24, 51-60]. However, according to the nature of the tissue used and the protein (antigen) under consideration, some protocols work better than others which are not yet well understood. Consequently, systematic tests of different AR protocols are required to define the best protocol. Here, we have tested several AR processes on prostate cancer FFPE tissues including EDTA pH 8 hot baths or in a pressure cooker, heat-induced AR using microwave and citric acid $\mathrm{pH} 6$ or CAAR in a hot bath. CAAR was found to provide better results for prostate cancer tissue sections with respect to trypsin digestion approach. We have performed a bottomup analysis of FFPE tissue from grade IV prostate cancer samples using trypsin as the enzyme and HCCA/ANI as the matrix, with a micro-spraying device. In a grade IV 
carcinoma section, several histological cell types were observed that resembled tumor or stroma with normal acini (close to normal) regions, as classified by the pathologist. Thus, the spectra of these two specific regions were collected before they were exported for the HC and PCA analyses (Fig. 8A). The dendrogram from the hierarchical clustering divides the spectra into two branches. The locations of these branches are shown in Fig. 8B. Classification of the spectra correlated with their histological origin (cancer grade IV in red vs. stroma with acini in green; Fig. 8B). This ranking suggests that it is possible to use the MS profiles (in this context, peptides and proteins) as a "signature" for cell phenotype classification or MSI histology, and it may allow the development of a new diagnostic approach based on the molecular signature and not on a specific biomarker alone. To illustrate this idea, two ROIs (ROI1 and ROI2) that were determined in different regions of the tissue were added to the analysis (Fig. $8 \mathrm{C}$ ) together with the previous regions. $\mathrm{HC}$ analysis was performed for these four regions. The resulting $\mathrm{HC}$ dendrogram revealed an initial separation into two branches and then a sub-division of each of these branches into two others. The first two branches (first division) were represented as an image on the tissue (Fig. 8D). In Fig. 8D, grade IV tumor and stroma with acini clusters can still be observed as distinct areas, with each area corresponding to a branch. However, it should be noted that the ROI1 spectra appear close to the stroma and tumor profiles, whereas ROI2 has a profile that is closer to the tumor alone. However, based on the sub-branch dendrogram analysis (Fig. 8E), we note that the turquoise blue cluster of ROI2 differs from the red cluster of the tumor and correspond to a sub-division. In contrast, ROI1 consistently shows a signature that is closer to the tumor and the stroma with acini. Therefore, it is possible to use the same approach for different biopsies and to correlate the signatures of the clusters obtained for the examined histological areas using a bank of peptide/protein signatures
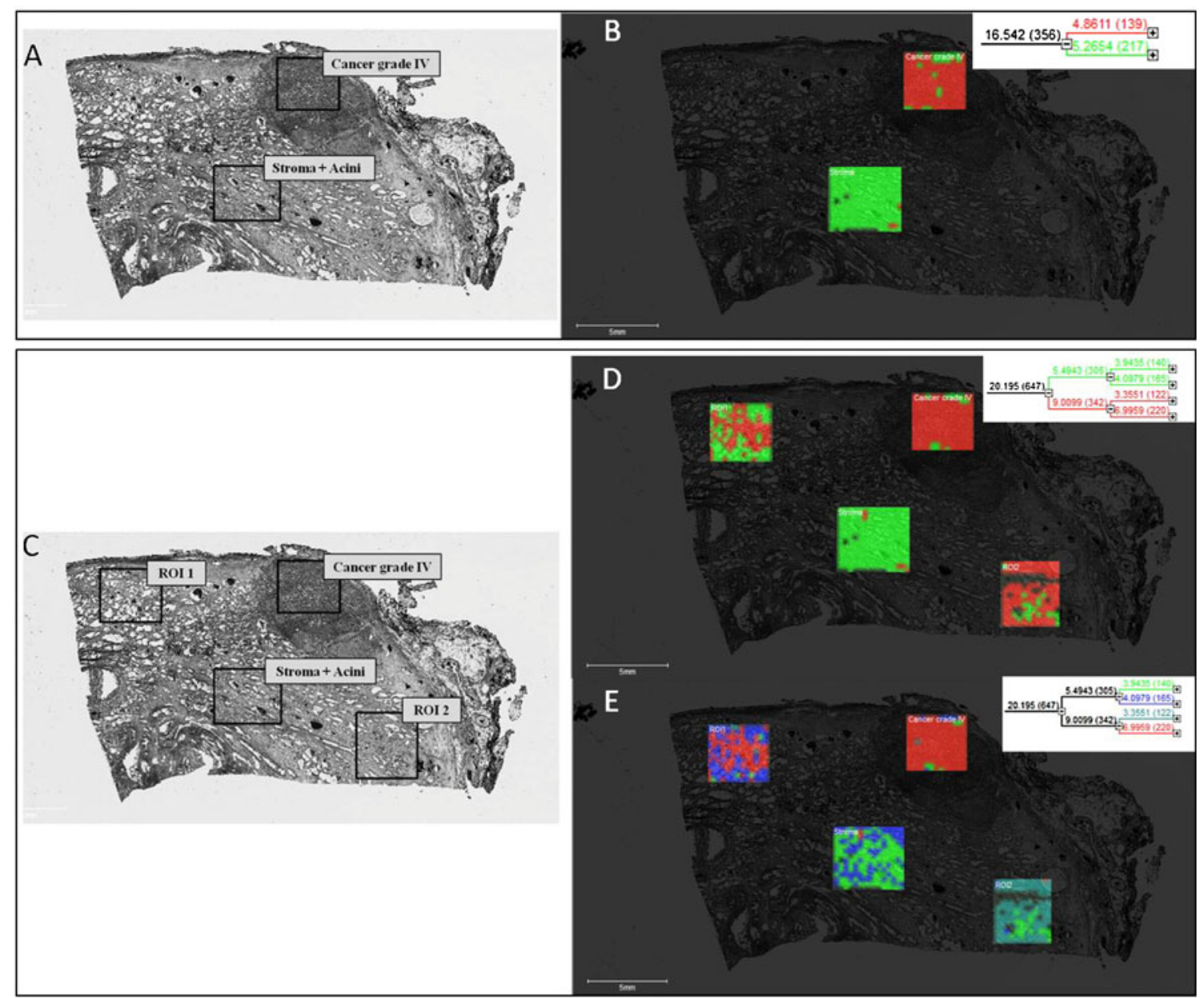

Fig. $8 \mathrm{HC}$ analysis of FFPE prostate cancer tissue after on-tissue trypsin digestion. A Delimitation of stroma with acini and cancer grade IV regions on the optical image of the tissue. B HC results (dendrogram and image) for the cancer and stroma with acini spectra.
C Delimitation of the new ROIs on the optical image of the tissue. D-E HC results (dendrogram and image) for four regions (stroma + acini, cancer, ROI1 and ROI2) 


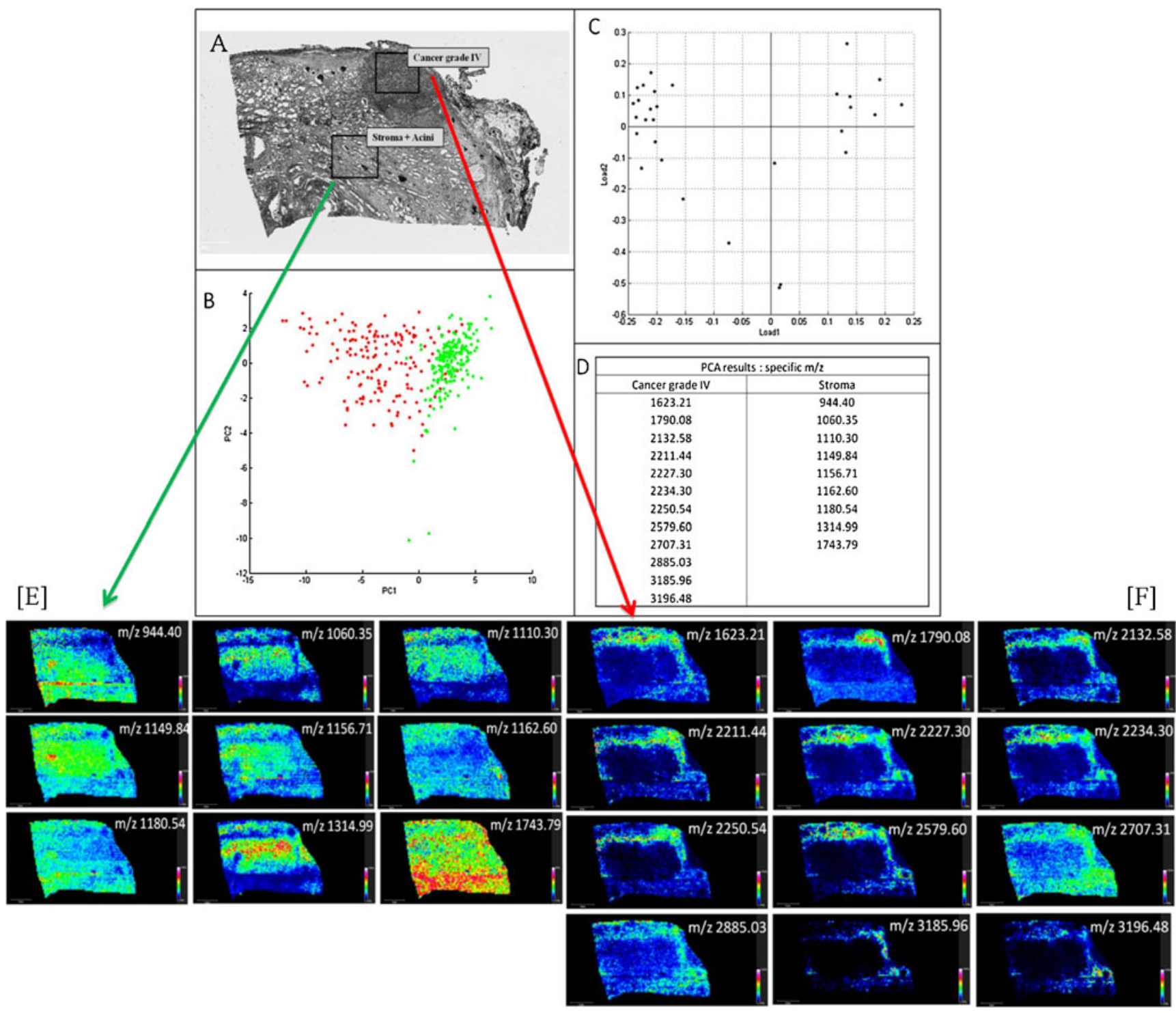

Fig. 9 Supervised PCA analysis of prostate cancer grade IV FFPE tissue after on-tissue trypsin digestion. A Optical images indicating the stroma with acini and cancer grade IV regions. B Score plot (green: stroma with acini spectra, red: cancer grade IV spectra). C Loading

generated from tissues for which the pathologic stages are known.

The spectral classification for the grade IV tumor and stroma with acini area also supports the conclusion that specific $\mathrm{m} / \mathrm{z}$ are related to the histologic classification. The PCA-SDA strategy can be performed to track markers for each cell phenotype (Fig. 9A). The score plot (Fig. 9B) and loading plot (Fig. 9C) obtained after supervised PCA analysis provides a list of $\mathrm{m} / \mathrm{z}$ that are specific to each area (Fig. 9D), determining clusters. Images of the ions detected in the stroma with acini are presented in Fig. 9E, and those detected in the tumor region are shown in Fig. 9F. To further understand the progression of cancer, it is of primary importance to identify the ions detected for each cell plot. D List of $m / z$ specific for each region. E-F MALDI-MSI images of the ions determined by PCA in the stroma with acini (E) and in the tumor region $(\mathbf{F})$

phenotype, i.e., tumor vs. stroma + acini. As described previously, enzymatic digestion does not lead to delocalization and allows a hierarchical classification. The PCA analysis related to the tissue type to be performed to highlight the presence of specific markers in the different cell types. Therefore, the bottom-up approach could be

Fig. 10 A MALDI-MSI molecular images of several fragments of actin tryptic fragments detected by PCA-SDA from the tissue section after AR and trypsin digestion, $\mathbf{B} \mathrm{MS} / \mathrm{MS}$ spectra of these actin tryptic fragments and $\mathbf{C}$ sequence coverage if these four fragments on the actin protein sequence. These images and MS/MS data were generated from the adjacent tissue section of the same patient biopsy used in the experiments corresponding to images presented Fig. 9 


\section{[A]}

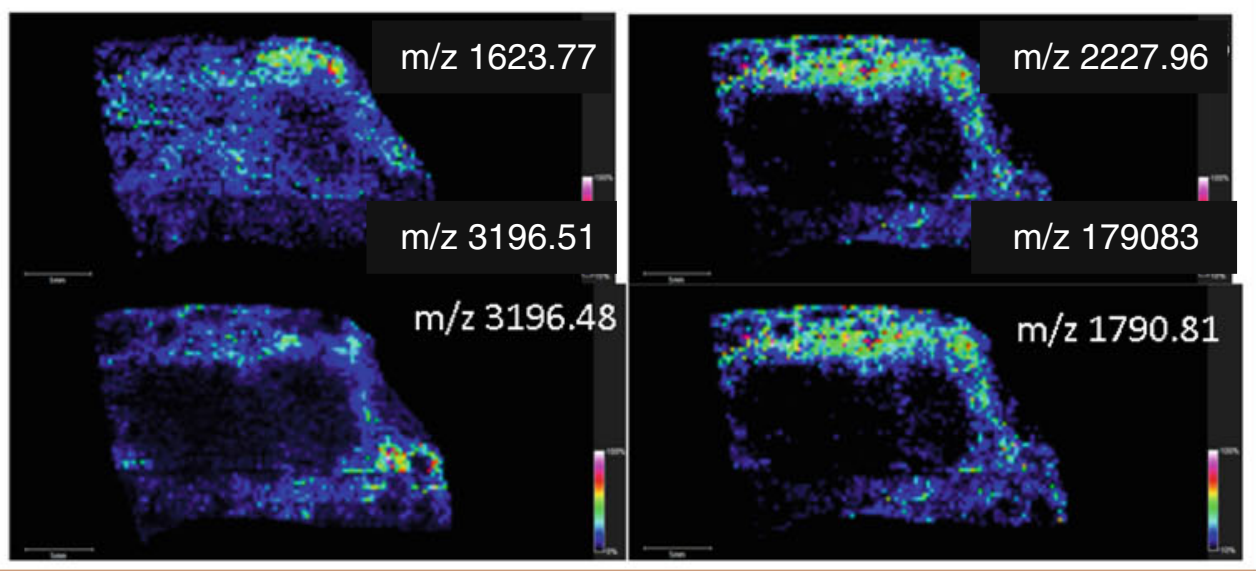

[B]

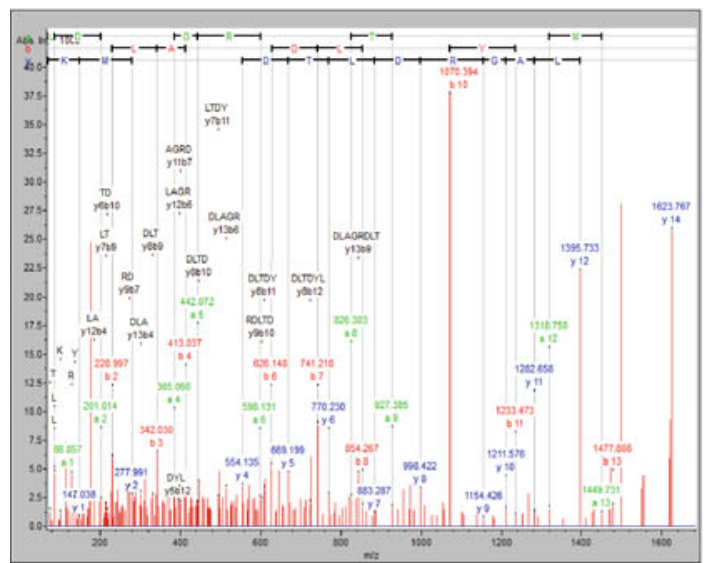

$\mathrm{m} / \mathrm{z} 3196.51$

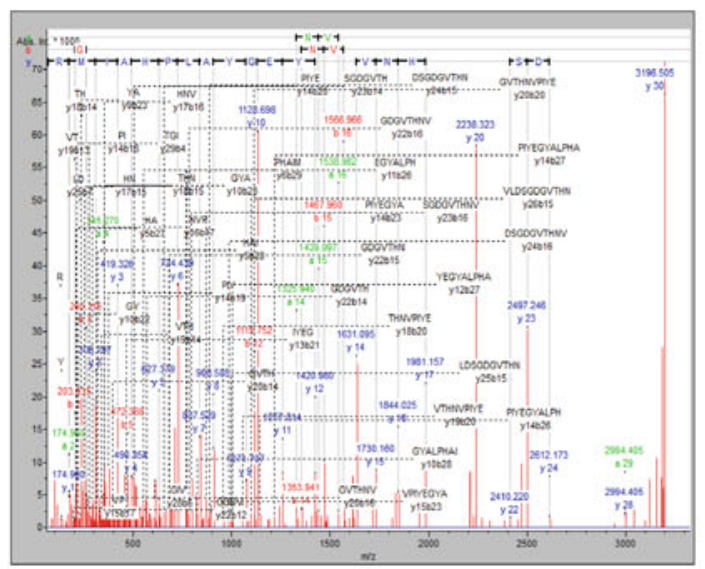

$\mathrm{m} / \mathrm{z} 2227.96$

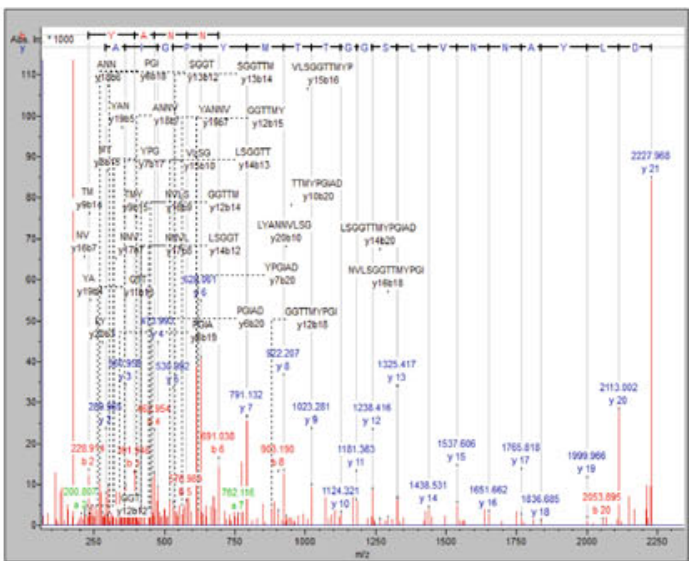

m/z 1790.83

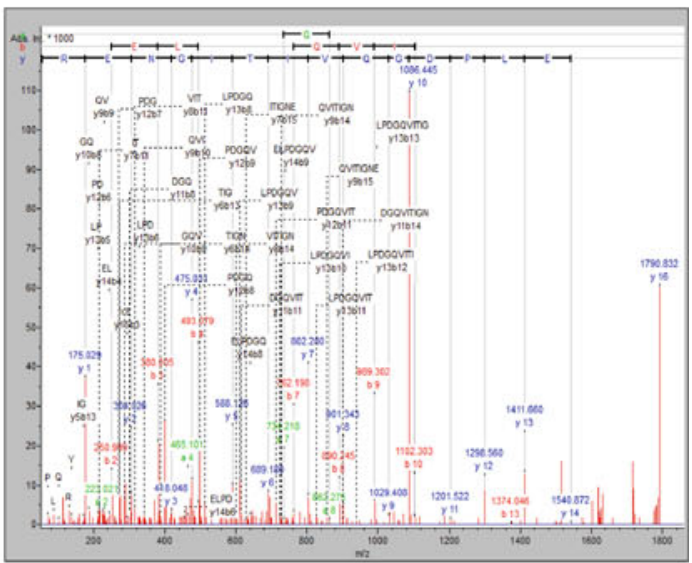

[C]

\begin{tabular}{|c|c|c|c|c|c|c|c|c|c|c|}
\hline 10 & 20 & 30 & 40 & 50 & 60 & 70 & 80 & 90 & 100 & 110 \\
\hline MCEEETTALV & CDNGSGLCKA & GFAGDDAPRA & VFPSIVGRPR & HQGVIVGMGQ & KDSYVGDEAQ & SKRGILTLKY & PIEHGIITNK & DDMEKIWHHS & FYNELRVAPE & EHPTLLTEAP \\
\hline 120 & 130 & 140 & 150 & 160 & 170 & 180 & 190 & 200 & 210 & 220 \\
\hline LNPKANREKM & TQIMFETENV & PAMYVAIQAV & LSLYASGRIT & GIVLDSGDGV & THNVPIYEGY & ALPHATMRLD & LAGRDLTDYL & MKILTERGYS & FVTTAEREIV & RDIKEKLCYV \\
\hline 230 & 240 & 250 & 260 & 270 & 280 & 290 & 300 & 310 & 320 & 330 \\
\hline ALDFENEMAT & AASSSSLERS & YELPDGQVIT & IGNERFRCPE & TLFQPSEIGM & ESAGIHETTY & NSIMRCDIDI & RRDLYANNVL & SGGTTMYPGI & ADRMQREITA & LAPSTMIRIRI \\
\hline 340 & 350 & 360 & 370 & 380 & & & & & & \\
\hline
\end{tabular}


useful for analyses of FFPE tissues from pathologist libraries. Some ions obtained using PCA-SDA were directly identified in the tissue section after the CAAR antigen retrieval procedure by $\mathrm{MS}^{2}$ using the MALDI-TOF/TOF instrument. A second experiment was performed from the adjacent tissue section of the FFPE biopsy block. Same MS profiles were again observed with an identical correlation of ions distribution with respect to the morphology of the tissue according to cell phenotypes. From this tissue $\mathrm{MS}^{2}$ experiments were undertaken for identification of proteins. $\mathrm{MS}^{2}$ was performed for precursor ions at $\mathrm{m} / \mathrm{z}$ 944.4, $1,180.54,1,623.21,1,743.79,1,790.08,2,227.30$, and
3,196.48 (Figs. 10 and 11). These ions correspond to actin fragments (Fig. 10B) or to histone H4, histone 2A type 1-A, and histone 2B type 1-B (Fig. 11). Interestingly, all of the actin fragments were specifically localized in the tumor region and not in the stroma with normal acini, which is consistent with the PCA-SDA results (Fig. 10A), whereas the histone fragments were localized in the stroma with acini (Fig. 8E). The ions related to actin present in the tumor region presented sequence coverage of $21.5 \%$ and were localized to the C-terminal portion of the protein, which suggested that the $\mathrm{N}$-terminal portion of the protein was less accessible due to the presence of methylene bonds or to
Fig. 11 MS/MS spectra recorded from prostate cancer FFPE tissue sections after AR and trypsin digestion of three different ions (three histones) found by PCA-SDA to be specifics of the stroma with acini region
[A]

Histone H2A type 1-A

$\mathrm{m} / \mathrm{z} 944.40$

AGLQFPVGR
[B]

Histone $\mathrm{H} 4$

$\mathrm{m} / \mathrm{z} 1180.54$

ISGLIYEETR
[C]

Histone H2B type 1-B $\mathrm{m} / \mathrm{z} 1743.79$

AMGIMNSFVNDIFER
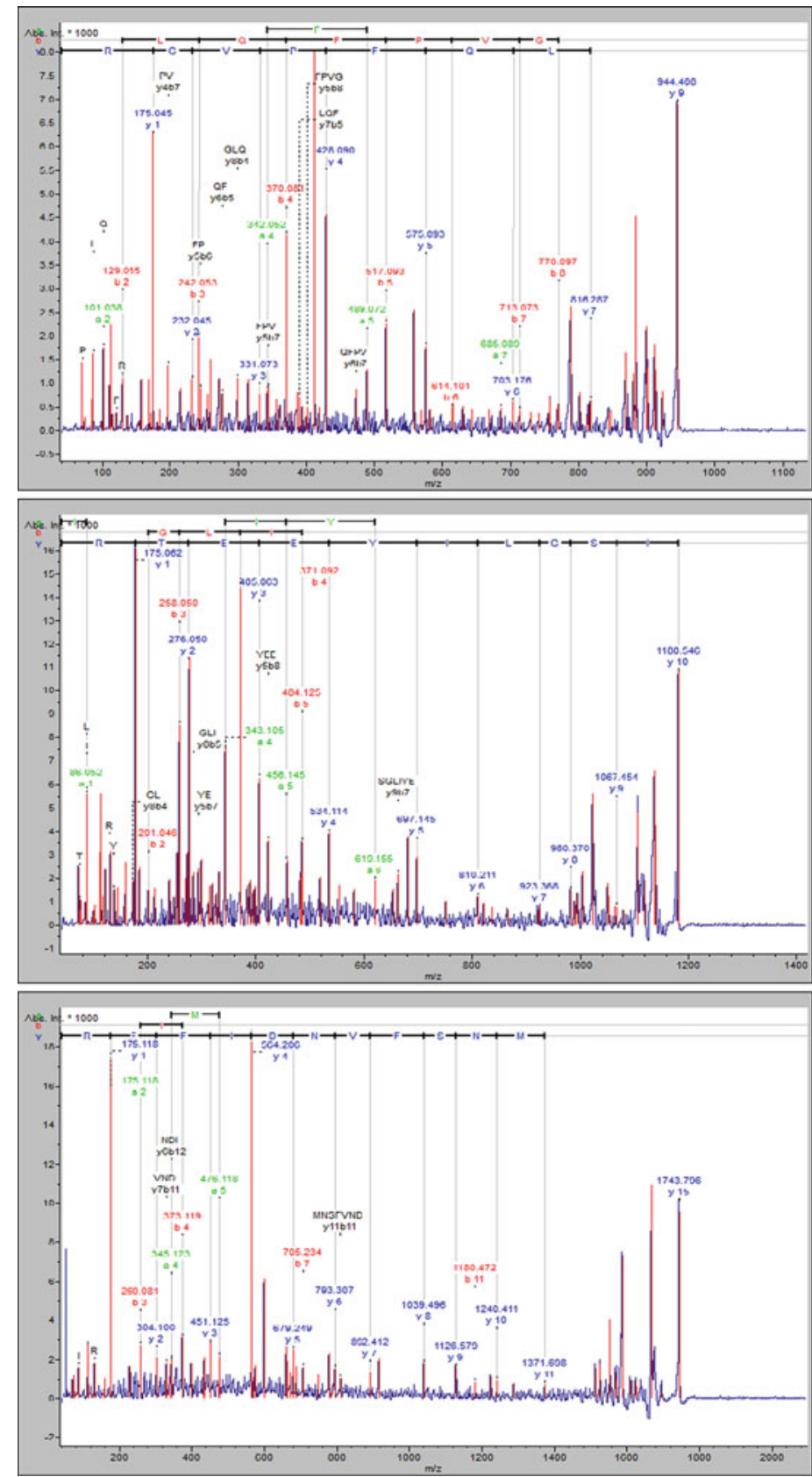
protein truncation (Fig. 10C). All the identified proteins, related tryptic peptide sequences, identification scores and $\mathrm{Mw}$ are summarized in Table 2. Ions attributing to the different MS/MS spectra corresponding to the different tryptic fragments studied are summarized in Electronic Supplementary Material Table S1. These experiments were reiterated on another FFPE block from a different patient performing experiments in triplicate from adjacent tissue slices. Similar results were obtained from this second patient. Identical ions were observed from this biopsy and ions distribution were again correlated to the same cells according to their morphological type (cell phenotype) The presence of actin in the tumor region is consistent with the cytoskeletal remodeling that occurs during prostate cancer development together with muscle contraction. The detection of histone types in the stroma with acini seems to indicate mitotic and apoptotic indices for these cells, which reflects the possibility that their phenotype is more similar to benign than to healthy cells. These data are consistent with the results obtained for other cancers, such as breast [50] or ovarian [18] cancers. Interestingly, we showed that based on the $150 \mathrm{~m} / \mathrm{z}$ detection using PCA-SDA in the tumor region, only four were related to actin. This result supports the finding that not only major proteins can be detected using the bottom-up strategy. These findings highlight the necessity to develop new approaches to gain access to the minor $\mathrm{m} / \mathrm{z}$ detected using PCA-SDA. In fact, AR followed by enzymatic digestion is not sufficient for the identification of these markers or for other minor ones. Nevertheless, several MS/MS studies have been performed, and identification problems have been encountered due to the methylene bridges that occur between proteins. In fact, in some cases, MS/MS spectra were uninterpretable and did not provide any identification results. This phenomenon was presumably attributed to the presence of cross-linked peptides that were linked by a methylene bridge. Thus, fundamental investigations are necessary to fully understand the chemistry of fixation and the formation of methylene bridges to develop the appropriate software for MS/MS spectral analysis from FFPE tissues.

\section{Conclusion}

The PCA-SDA based on hierarchical clustering represents an excellent, fast, and reproducible technique for the analysis of MSI data to search for markers. We showed that this approach is useful after different tissue treatments, such as enzyme digestion and $\mathrm{N}$-terminal derivatization, which are used in bottom-up strategies for the direct identification of ions of interest in the tissue. Thus, it is possible to combine the MALDI-MSI and bottom-up approach for protein identification. This can be conducted

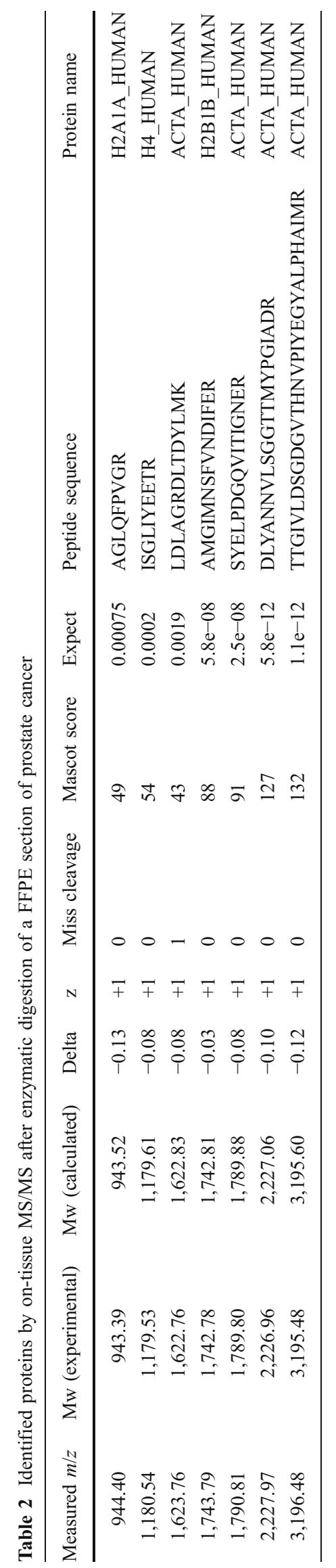


via enzymatic digestion, derivatization, and PCA-SDA based on hierarchical clustering for protein fragment detection and identification. All of these steps can be performed for the same tissue and in only one experiment. Data obtained using the top-down method with ISD can also be used for PCA-SDA following on-tissue depletion to highlight proteins other than the major ones. In the near future, the most promising development will be the emergence of databases that are based on approaches using these statistical models. The creation of mathematical models that represent histological groups could enable a significant advance for molecularly based diagnostic and prognostic studies.

Acknowledgments This research was supported by grants from Centre National de la Recherche Scientifique (CNRS), Ministère de L'Education Nationale, de L'Enseignement Supérieur et de la Recherche, Agence Nationale de la Recherche (ANR PCV to IF), Institut du Cancer (INCA to IF), Région Nord-Pas de Calais (PhD financing to DB and RL), the Canadian Institutes of Health Research (CIHR to RD) and the Ministère du Développement Économique, de l'Innovation et de l'Exportation (MDEIE to RD) du Québec and the Fonds de recherche en santé du Québec (FRSQ to RD). RD is a member of the Centre de Recherche Clinique Étienne-Le Bel (Sherbrooke, QC, Canada).

\section{References}

1. Caprioli RM, Farmer TB, Gile J (1997) Molecular imaging of biological samples: localization of peptides and proteins using MALDI-TOF MS. Anal Chem 69(23):4751-4760

2. McLean JA, Ridenour WB, Caprioli RM (2007) Profiling and imaging of tissues by imaging ion mobility-mass spectrometry. J Mass Spectrom 42(8):1099-1105

3. Sugiura Y, Shimma S, Konishi Y, Yamada MK, Setou M (2008) Imaging mass spectrometry technology and application on ganglioside study; visualization of age-dependent accumulation of C20-ganglioside molecular species in the mouse hippocampus. PLoS ONE 3(9):e3232

4. Landgraf RR, Prieto Conaway MC, Garrett TJ, Stacpoole PW, Yost RA (2009) Imaging of lipids in spinal cord using intermediate pressure matrix-assisted laser desorption-linear ion trap/Orbitrap MS. Anal Chem 81(20):8488-8495

5. Taban IM, Altelaar AF, van der Burgt YE, McDonnell LA, Heeren RM, Fuchser J, Baykut G (2007) Imaging of peptides in the rat brain using MALDI-FTICR mass spectrometry. J Am Soc Mass Spectrom 18(1):145-151

6. Sugiura Y, Setou M (2009) Imaging mass spectrometry for visualization of drug and endogenous metabolite distribution: toward in situ pharmacometabolomes. J Neuroimmune Pharmacol

7. Khatib-Shahidi S, Andersson M, Herman JL, Gillespie TA, Caprioli RM (2006) Direct molecular analysis of whole-body animal tissue sections by imaging MALDI mass spectrometry. Anal Chem 78(18):6448-6456

8. Prideaux B, Staab D, Stoeckli M (2010) Applications of MALDIMSI to pharmaceutical research. Methods Mol Biol 656:405-413

9. Stoeckli MSD, Schweitzer A (2007) Compound and metabolite distribution measured by MALDI mass spectrometric imaging in whole-body tissue sections. Int J Mass Spectrom 260:195-202
10. Franck J, Arafah K, Barnes A, Wisztorski M, Salzet M, Fournier I (2009) Improving tissue preparation for matrix-assisted laser desorption ionization mass spectrometry imaging. Part 1: using microspotting. Anal Chem 81(19):8193-8202

11. Lemaire R, Wisztorski M, Desmons A, Tabet JC, Day R, Salzet M, Fournier I (2006) MALDI-MS direct tissue analysis of proteins: improving signal sensitivity using organic treatments. Anal Chem 78(20):7145-7153

12. Seeley EH, Caprioli RM (2008) Molecular imaging of proteins in tissues by mass spectrometry. Proc Natl Acad Sci USA 105 (47):18126-18131

13. Jardin-Mathe O, Bonnel D, Franck J, Wisztorski M, Macagno E, Fournier I, Salzet M (2008) MITICS (MALDI imaging team imaging computing system): a new open source mass spectrometry imaging software. J Proteomics

14. Stoeckli M, Farmer TB, Caprioli RM (1999) Automated mass spectrometry imaging with a matrix-assisted laser desorption ionization time-of-flight instrument. J Am Soc Mass Spectrom 10(1):67-71

15. Chaurand P, Schriver KE, Caprioli RM (2007) Instrument design and characterization for high resolution MALDI-MS imaging of tissue sections. J Mass Spectrom 42(4):476-489

16. Koestler M, Kirsch D, Hester A, Leisner A, Guenther S, Spengler B (2008) A high-resolution scanning microprobe matrix-assisted laser desorption/ionization ion source for imaging analysis on an ion trap/Fourier transform ion cyclotron resonance mass spectrometer. Rapid Commun Mass Spectrom 22(20):3275-3285

17. Caprioli RM (2008) Perspectives on imaging mass spectrometry in biology and medicine. Proteomics 8(18):3679-3680

18. El Ayed M, Bonnel D, Longuespee R, Castelier C, Franck J, Vergara D, Desmons A, Tasiemski A, Kenani A, Vinatier D, Day R, Fournier I, Salzet M (2010) MALDI imaging mass spectrometry in ovarian cancer for tracking, identifying, and validating biomarkers. Med Sci Monit 16(8):BR233-45

19. Franck J, Arafah K, Elayed M, Bonnel D, Vergara D, Jacquet A, Vinatier D, Wisztorski M, Day R, Fournier I, Salzet M (2009) MALDI imaging mass spectrometry: state of the art technology in clinical proteomics. Mol Cell Proteomics 8(9):2023-2033

20. McDonnell LA, Corthals GL, Willems SM, van Remoortere A, van Zeijl RJ, Deelder AM Peptide and protein imaging mass spectrometry in cancer research. J Proteomics 73(10):1921-1944

21. Wisztorski M, Croix D, Macagno E, Fournier I, Salzet M (2008) Molecular MALDI imaging: an emerging technology for neuroscience studies. Dev Neurobiol 68(6):845-858

22. Wisztorski M, Lemaire R, Stauber J, Menguelet SA, Croix D, Mathe OJ, Day R, Salzet M, Fournier I (2007) New developments in MALDI imaging for pathology proteomic studies. Curr Pharm Des 13(32):3317-3324

23. Bakry R, Rainer M, Huck CW, Bonn GK (2011) Protein profiling for cancer biomarker discovery using matrix-assisted laser desorption/ionization time-of-flight mass spectrometry and infrared imaging: a review. Anal Chim Acta 690(1):26-34

24. Gustafsson JO, Oehler MK, McColl SR, Hoffmann P (2010) Citric acid antigen retrieval (CAAR) for tryptic peptide imaging directly on archived formalin-fixed paraffin-embedded tissue. $\mathrm{J}$ Proteome Res 9(9):4315-4328

25. Drake RR, Cazares LH, Jones EE, Fuller TW, Semmes OJ, Laronga C (2011) Challenges to developing proteomic-based breast cancer diagnostics. OMICS (in press)

26. Seeley EH, Caprioli RM (2011) MALDI imaging mass spectrometry of human tissue: method challenges and clinical perspectives. Trends Biotechnol 29(3):136-143

27. Van de Plas R, Ojeda F, Dewil M, Van Den Bosch L, De Moor B, Waelkens E (2007) Prospective exploration of biochemical tissue composition via imaging mass spectrometry guided by principal component analysis. Pac Symp Biocomput 2007:458-469 
28. Deininger SO, Ebert MP, Futterer A, Gerhard M, Rocken C (2008) MALDI imaging combined with hierarchical clustering as a new tool for the interpretation of complex human cancers. J Proteome Res

29. Walch A, Rauser S, Deininger SO, Hofler H (2008) MALDI imaging mass spectrometry for direct tissue analysis: a new frontier for molecular histology. Histochem Cell Biol 130(3):421-434

30. Trim PJ, Atkinson SJ, Princivalle AP, Marshall PS, West A, Clench MR (2008) Matrix-assisted laser desorption/ionisation mass spectrometry imaging of lipids in rat brain tissue with integrated unsupervised and supervised multivariant statistical analysis. Rapid Commun Mass Spectrom 22(10):1503-1509

31. Franck J, Ayed ME, Wisztorski M, Salzet M, Fournier I (2010) On tissue protein identification improvement by $\mathrm{N}$-terminal peptide derivatization. Methods Mol Biol 656:323-338

32. Franck J, El Ayed M, Wisztorski M, Salzet M, Fournier I (2009) On-tissue $\mathrm{N}$-terminal peptide derivatizations for enhancing protein identification in MALDI mass spectrometric imaging strategies. Anal Chem 81(20):8305-8317

33. Debois D, Bertrand V, Quinton L, De Pauw-Gillet MC, De Pauw E (2010) MALDI-in source decay applied to mass spectrometry imaging: a new tool for protein identification. Anal Chem 82 (10):4036-4045

34. Seeley EH, Oppenheimer SR, Mi D, Chaurand P, Caprioli RM (2008) Enhancement of protein sensitivity for MALDI imaging mass spectrometry after chemical treatment of tissue sections. J Am Soc Mass Spectrom 19(8):1069-1077

35. Lemaire R, Desmons A, Tabet JC, Day R, Salzet M, Fournier I (2007) Direct analysis and MALDI imaging of formalin-fixed, paraffin-embedded tissue sections. J Proteome Res 6(4):12951305

36. Groseclose MR, Andersson M, Hardesty WM, Caprioli RM (2007) Identification of proteins directly from tissue: in situ tryptic digestions coupled with imaging mass spectrometry. J Mass Spectrom 42(2):254-262

37. Stauber J, Lemaire R, Franck J, Bonnel D, Croix D, Day R, Wisztorski M, Fournier I, Salzet M (2008) MALDI imaging of formalin-fixed paraffin-embedded tissues: application to model animals of Parkinson disease for biomarker hunting. J Proteome Res 7(3):969-978

38. Wisztorski M, Franck J, Salzet M, Fournier I (2010) MALDI direct analysis and imaging of frozen versus FFPE tissues: what strategy for which sample? Methods Mol Biol 656:303-322

39. Reiber DC, Grover TA, Brown RS (1998) Identifying proteins using matrix-assisted laser desorption/ionization in-source fragmentation data combined with database searching. Anal Chem 70 (4):673-683

40. Reiber DC, Brown RS, Weinberger S, Kenny J, Bailey J (1998) Unknown peptide sequencing using matrix-assisted laser desorption/ionization and in-source decay. Anal Chem 70(6):1214-1222

41. Brown RS, Lennon JJ (1995) Sequence-specific fragmentation of matrix-assisted laser-desorbed protein/peptide ions. Anal Chem 67 (21):3990-3999

42. Hardouin J (2007) Protein sequence information by matrixassisted laser desorption/ionization in-source decay mass spectrometry. Mass Spectrom Rev 26(5):672-682

43. Takayama M, Tsugita A (2000) Sequence information of peptides and proteins with in-source decay in matrix assisted laser desorption/ionization-time of flight-mass spectrometry. Electrophoresis 21(9):1670-1677

44. Takayama M (2001) In-source decay characteristics of peptides in matrix-assisted laser desorption/ionization time-of-flight mass spectrometry. J Am Soc Mass Spectrom 12(4):420-427
45. Suckau D, Resemann A (2003) T3-sequencing: targeted characterization of the $\mathrm{N}$ - and $\mathrm{C}$-termini of undigested proteins by mass spectrometry. Anal Chem 75(21):5817-5824

46. Resemann A, Wunderlich D, Rothbauer U, Warscheid B, Leonhardt H, Fuchser J, Kuhlmann K, Suckau D Top-down de Novo protein sequencing of a $13.6 \mathrm{kDa}$ camelid single heavy chain antibody by matrix-assisted laser desorption ionizationtime-of-flight/time-of-flight mass spectrometry. Anal Chem 82 (8):3283-3292

47. Demeure K, Quinton L, Gabelica V, De Pauw E (2007) Rational selection of the optimum MALDI matrix for top-down proteomics by in-source decay. Anal Chem 79(22):8678-8685

48. Groseclose MR, Massion PP, Chaurand P, Caprioli RM (2008) High-throughput proteomic analysis of formalin-fixed paraffinembedded tissue microarrays using MALDI imaging mass spectrometry. Proteomics 8(18):3715-3724

49. Ronci M, Bonanno E, Colantoni A, Pieroni L, Di Ilio C, Spagnoli LG, Federici G, Urbani A (2008) Protein unlocking procedures of formalin-fixed paraffin-embedded tissues: application to MALDI-TOF imaging MS investigations. Proteomics 8(18):3702-3714

50. Djidja MC, Francese S, Loadman PM, Sutton CW, Scriven P, Claude E, Snel MF, Franck J, Salzet M, Clench MR (2009) Detergent addition to tryptic digests and ion mobility separation prior to MS/MS improves peptide yield and protein identification for in situ proteomic investigation of frozen and formalin-fixed paraffin-embedded adenocarcinoma tissue sections. Proteomics 9 (10):2750-2763

51. Tian Y, Zhang H (2010) Isolation of proteins by heat-induced extraction from formalin-fixed, paraffin-embedded tissue and preparation of tryptic peptides for mass spectrometric analysis. Curr Protoc Mol Biol Chapter 10, Unit 1026 1-7

52. Xu H, Yang L, Wang W, Shi SR, Liu C, Liu Y, Fang X, Taylor CR, Lee CS, Balgley BM (2008) Antigen retrieval for proteomic characterization of formalin-fixed and paraffin-embedded tissues. J Proteome Res 7(3):1098-1108

53. Shi SR, Liu C, Perez J, Taylor CR (2005) Protein-embedding technique: a potential approach to standardization of immunohistochemistry for formalin-fixed, paraffin-embedded tissue sections. J Histochem Cytochem 53(9):1167-1170

54. D'Amico F, Skarmoutsou E, Stivala F (2009) State of the art in antigen retrieval for immunohistochemistry. J Immunol Methods 341(1-2):1-18

55. Yamashita S (2007) Heat-induced antigen retrieval: mechanisms and application to histochemistry. Prog Histochem Cytochem 41 (3): $141-200$

56. Shi SR, Cote RJ, Taylor CR (2001) Antigen retrieval techniques: current perspectives. J Histochem Cytochem 49(8):931-937

57. Shi SR, Cote RJ, Taylor CR (2001) Antigen retrieval immunohistochemistry and molecular morphology in the year 2001. Appl Immunohistochem Mol Morphol 9(2):107-116

58. Shi SR, Datar R, Liu C, Wu L, Zhang Z, Cote RJ, Taylor CR (2004) DNA extraction from archival formalin-fixed, paraffinembedded tissues: heat-induced retrieval in alkaline solution. Histochem Cell Biol 122(3):211-218

59. Shi SR, Shi Y, Taylor CR (2007) Updates on antigen retrieval techniques for immunohistochemistry. Zhonghua Bing Li Xue Za Zhi 36(1):7-10

60. Shi SR, Liu C, Young L, Taylor C (2007) Development of an optimal antigen retrieval protocol for immunohistochemistry of retinoblastoma protein $(\mathrm{pRB})$ in formalin fixed, paraffin sections based on comparison of different methods. Biotech Histochem 82 (6):301-9 